\title{
Neuromodulation for treatment-resistant depression
}

\author{
Paul E. Holtzheimer ${ }^{1 *}$ and Helen S. Mayberg ${ }^{2}$
}

Addresses: ${ }^{1}$ Departments of Psychiatry and Surgery, Dartmouth-Hitchcock Medical Center, 5D, One Medical Center Drive, Lebanon NH 03756, USA; ${ }^{2}$ Departments of Psychiatry and Neurology, Emory University School of Medicine, 1648 Pierce Drive Northeast, Atlanta, GA 30307, USA

*Corresponding authors: Paul E. Holtzheimer (Paul.E.Holtzheimer@hitchcock.org); Helen S. Mayberg (hmayber@emory.edu)

FI000 Medicine Reports 2012, 4:22 (doi:10.3410/M4-22)

This is an open-access article distributed under the terms of the Creative Commons Attribution-Non Commercial License (http://creativecommons.org/licenses/by-nc/3.0/legalcode), which permits unrestricted use, distribution, and reproduction in any medium, provided the original work is properly cited. You may not use this work for commercial purposes.

The electronic version of this article is the complete one and can be found at: http://f1000.com/reports/m/4/22

\begin{abstract}
Treatment-resistant depression affects at least I-3\% of the US population. This article reviews the current state of focal neuromodulation therapies for treatment-resistant depression, having published clinical data. These include transcranial magnetic stimulation, transcranial direct current stimulation, magnetic seizure therapy, vagus nerve stimulation, direct cortical stimulation, and deep brain stimulation among others. Of these, only two (transcranial magnetic stimulation and vagus nerve stimulation) currently have US Food and Drug Administration approval for the treatment of depression.
\end{abstract}

\section{Introduction}

Major depression is one of the most prevalent and costly medical conditions worldwide $[1,2]$. Antidepressant medications and psychotherapy, the most common firstline therapies for depression, are effective for many patients, though a sizable minority (10-40\%) remain significantly treatment resistant $[3,4]$. Treatment-resistant depression therefore affects at least $1-3 \%$ of the US population.

Historically, electroconvulsive therapy and ablative neurosurgery have been the treatments available for patients with varying degrees of severe, treatment-resistant depression. Ablative neurosurgery (including, anterior capsulotomy, dorsal cingulotomy, and subcaudate tractotomy) evolved from early anatomical theories of mood regulation and has been consistently used for the most severely ill and treatment-resistant depressed patients. Although efficacy has been suggested, side effects are common, thus limiting use [5-8]. Electroconvulsive therapy, first introduced in 1938, also predates medications as a treatment for depression [9] and remains the most effective antidepressant treatment available, with acute remission rates around $60 \%$, even in treatment-resistant patients $[10,11]$. Electroconvulsive therapy is administered by delivering electricity directly to the brain via scalp electrodes to induce a generalized seizure. A series of seizures (typically 9-12) are given over several weeks. Cognitive side effects, including post-ictal confusion, anterograde amnesia (difficulty encoding new memories during the course of electroconvulsive therapy) and retrograde amnesia (loss of memory for events that occurred prior to electroconvulsive therapy) can occur and are typically transient and well-tolerated. Changes in electroconvulsive therapy methods, such as the use of right unilateral electrode placement and the introduction of ultrabrief pulse stimulation, have attempted to minimize cognitive side effects without sacrificing efficacy. However, cognitive side effects, stigma and practical concerns (e.g. needing to take time off work) continue to limit the utility of electroconvulsive therapy. Further attempts to optimize electroconvulsive therapy or electroconvulsive therapylike treatments include magnetic seizure therapy (discussed below) and focal electrically-administered seizure therapy ([12] FEAST), which is now in clinical trials (clinicaltrials.gov identifier NCT01589315).

Focal neuromodulation offers a potential alternative, nonpharmacologic approach for treatment-resistant depression. Broadly defined, neuromodulation involves directly altering the function of a specific neural structure with the intent of modulating activity throughout a neural network of brain regions implicated in depression. Current neuromodulation therapies have largely emerged 
from electroconvulsive therapy and ablative neurosurgery, coupled with neuroimaging data from studies of depression and antidepressant treatment response. Together, electroconvulsive therapy and ablative neurosurgery represent early attempts at "neuromodulation". Although medications and psychotherapy likely alter the function of the neural networks involved in depression, the targets of these treatments are not specific neural structures. Alternatively, developing neuromodulation strategies aim to primarily affect activity of a specific brain region with the expectation of unique, secondary alterations of function throughout the "depression network".

This article will review the current state of focal neuromodulation treatments for depression, with the scope limited to those treatments with published clinical data. Specific treatments to be reviewed include transcranial magnetic stimulation, transcranial direct current stimulation, magnetic seizure therapy, vagus nerve stimulation, direct cortical stimulation, and deep brain stimulation among others. Of these, only two (transcranial magnetic stimulation and vagus nerve stimulation) have US Food and Drug Administration (FDA) approval for the treatment of depression.

The rationale for neuromodulation for depression is based on a neural network theory that posits a specific set of structurally and functionally connected brain regions that work together to maintain normal mood regulation $[13,14]$. Depression is hypothesized to arise from dysfunctional communication between nodes within this network. For all of the techniques discussed below, the general mechanism of action is presumed to be modulation of the "depression" network, often through "downstream" effects on brain regions remote from the actual target of stimulation. However, which nodes and/or connections must be affected for an adequate antidepressant effect may differ between methods, resulting in different initial targets of stimulation. Additionally, different targets for neuromodulation may be chosen in an effort to improve the safety of the intervention while maintaining antidepressant benefit (e.g. developing focal magnetic seizure therapy as an alternative to electroconvulsive therapy).

\section{Transcranial magnetic stimulation}

Transcranial magnetic stimulation uses a rapidly alternating magnetic field to induce an electric current in underlying cortex, depolarizing cortical neurons [15]. Transcranial magnetic stimulation is non-invasive and requires no anesthesia. Each treatment involves delivery of multiple stimuli in a series of trains over about an hour. Treatments are typically given daily, five times per week, for three to six weeks (most of the treatment trials described below used 10-20 treatments). Transcranial magnetic stimulation is generally very well-tolerated, though scalp pain and headaches may be associated with stimulation, and seizure is a rare potential adverse effect. [16-18]. Transcranial magnetic stimulation is FDA-approved for the treatment of depression that has not responded to one antidepressant medication.

Transcranial magnetic stimulation has been studied as a treatment for depression for nearly 20 years, and a number of meta-analyses and two large sham-controlled trials have confirmed that transcranial magnetic stimulation is associated with statistically significant antidepressant effects $[16,17,19-24]$. Although stimulation parameters have differed across studies, the most common settings include $5-20 \mathrm{~Hz}$ (high frequency) transcranial magnetic stimulation applied to the left dorsolateral prefrontal cortex at $80 \%-120 \%$ motor threshold (intensity needed to cause movement in a muscle group in half of 10 or more trials). Treatment courses have generally included 10 to 30 sessions (over 2-6 weeks). A few studies have used low-frequency $(\leq 1 \mathrm{~Hz})$ transcranial magnetic stimulation delivered over the right dorsolateral prefrontal cortex with evidence of efficacy [25]. Targeting the dorsolateral prefrontal cortex was based on this region consistently showing abnormal activity in depressed patients versus controls [26,27] as well as empirical data [28]. Additional studies have demonstrated that dorsolateral prefrontal cortex transcranial magnetic stimulation can alter activity in more distant brain regions implicated in the "depression" network (e.g. $[29,30])$.

Response and remission rates with transcranial magnetic stimulation for treatment-resistant depression, while statistically significant, have often been relatively low in shamcontrolled studies (20-40\% and $10-20 \%$ respectively). However, these are not dissimilar from response/remission rates seen for other antidepressant treatments in patients failing at least one prior treatment [3]. Transcranial magnetic stimulation is probably not more effective than optimally dosed electroconvulsive therapy [31-40], and likely has a role for the treatment of depression that is somewhat, but not extremely, treatment resistant.

Transcranial magnetic stimulation may also be appropriate for patients who do not tolerate or cannot take adequate doses of standard antidepressant medications (opening up the possibility for benefit in specific populations such as pregnant women [41-45], children [46-51] and the medically ill and/or elderly [52-57]).

Relapse rate following successful transcranial magnetic stimulation is not clear. To date, studies addressing this have had the following: inconsistent definitions of relapse vs. symptom worsening; different samples 
(e.g. responders vs. remitters); small sample size; and high loss to follow-up. That said, data to date are somewhat encouraging, and suggest relapse following transcranial magnetic stimulation may not be different from other acute treatments, such as electroconvulsive therapy. In one head-to-head study, the six-month relapse rates following electroconvulsive therapy vs. transcranial magnetic stimulation were identical (20\%) [58]. In another study, the sixmonth maintenance of response following an acute course was 44\% [59] - not dissimilar from that seen following electroconvulsive therapy [11]. In one large, multi-center trial, $58 \%$ of remitters to an acute course of transcranial magnetic stimulation maintained remission after an additional three months following the acute course [60]. In another large trial, $48 \%$ of patients either relapsed or had significant symptom worsening within the six months following successful transcranial magnetic stimulation [61]; of those patients with worsening symptoms, $84 \%$ achieved benefit from another course of transcranial magnetic stimulation. Repeated transcranial magnetic stimulation courses may help maintain initial benefit [62], suggesting that maintenance transcranial magnetic stimulation may have a role in the management of patients with depression similar to maintenance electroconvulsive therapy.

Attempts to optimize transcranial magnetic stimulation as a treatment for depression are underway and include combining high- with low-frequency treatments [63-68], developing "deep" transcranial magnetic stimulation systems that can stimulate structures below superficial cortex [69-73] and developing novel dosing strategies typically aimed at increasing the overall dose or shortening the treatment time for a given dose [74-78].

\section{Transcranial direct current stimulation}

Transcranial direct current stimulation delivers a low intensity direct current to the cortex via scalp electrodes. Unlike transcranial magnetic stimulation, transcranial direct current stimulation does not depolarize cortical neurons but may affect their excitability [79]. However, like transcranial magnetic stimulation, the mechanism of action is presumed to involve modulation of function of the regions stimulated with the potential for "downstream" effects throughout the depression neural network. Stimulation is non-invasive, requires no anesthesia and is very welltolerated $[80,81]$. Treatments are provided about five times per week over several weeks (similar to transcranial magnetic stimulation). As an alternative to transcranial magnetic stimulation, transcranial direct current stimulation may have fewer acute side effects, though it is based on the same rationale of directly altering dorsolateral prefrontal cortex function. Based on a small number of openand sham-controlled studies, transcranial direct current stimulation may have antidepressant effects in depressed patients [79,82-87]. Response and remission rates have not been consistently reported in the literature (and in one study did not differ between the active and sham group despite a statistically significant difference in change in depression severity [85]). Relapse rate following successful treatment has not been reported. A multi-site study of transcranial direct current stimulation compared to sertraline is ongoing [88], but, to date, transcranial direct current stimulation has not been compared to other brain stimulation therapies, such as transcranial magnetic stimulation.

\section{Transcranial low voltage pulsed electromagnetic fields}

Transcranial low voltage pulsed electromagnetic fields stimulation involves applying low intensity electromagnetic fields to the brain via a series of scalp coils. Targeted pulsed electromagnetic fields are non-invasive and require no anesthesia. Unlike transcranial direct current stimulation, targeted pulsed electromagnetic uses electromagnetic fields rather than direct electrical current to stimulate cortical neurons. Unlike transcranial magnetic stimulation, the electromagnetic fields are relatively static and not strong enough to actually depolarize cortical neurons. A 5-week sham-controlled study $(\mathrm{N}=50)$ reported statistically significant antidepressant effects for targeted pulsed electromagnetic [89], and it appears to be relatively safe and well-tolerated. It has not been compared to other brain stimulation therapies, and the potential mechanism of action is unknown.

\section{Magnetic seizure therapy}

Magnetic seizure therapy involves inducing a series of generalized seizures (similar to electroconvulsive therapy) using a transcranial magnetic stimulation device focused on the prefrontal cortex. To date, magnetic seizure therapy has shown open-label antidepressant efficacy (i.e. there are no data with patients blinded to treatment), though its relative efficacy/safety (including cognitive safety) compared to electroconvulsive therapy is not clear. Some studies have shown equivalent efficacy while others show that electroconvulsive therapy is superior; cognitive safety has either been equivalent or slightly better than electroconvulsive therapy [90-94]. There are currently no sham-controlled studies of magnetic seizure therapy for treatment-resistant depression. As with electroconvulsive therapy, the potential mechanism of action of magnetic seizure therapy is unknown.

\section{Vagus nerve stimulation}

Vagus nerve stimulation involves surgically attaching an electrode to a vagus nerve (typically the left) with electrical stimulation controlled by an implanted pulse 
generator. Vagus nerve stimulation was approved by the FDA for medication-refractory epilepsy in 1997 and for medication-refractory depression in 2005; however, in the US, the Center for Medicare and Medicaid Services, and most other insurers, do not cover the costs of vagus nerve stimulation for treatment-resistant depression. The rationale for vagus nerve stimulation as a treatment for depression was initially based on mood-elevating effects in implanted epilepsy patients without depression $[95,96]$. Additional justification was provided by several human and animal studies highlighting the ability of vagus nerve stimulation to alter activity in brain regions and neurotransmitter systems implicated in depression [97].

Open-label studies have shown a 30-40\% antidepressant response rate (defined as a $>50 \%$ decrease depression severity) and a $15-17 \%$ remission rate after 3-24 months of vagus nerve stimulation in treatment-resistant depression patients [98-103]. A large, sham-controlled study of vagus nerve stimulation for treatment-resistant depression showed no statistically significant benefit for 10 weeks of active vagus nerve stimulation [104], though open-label response/remission rates went up with more chronic, open-label treatment [100] and were higher than those seen with treatment-as-usual (without vagus nerve stimulation) in a non-randomized comparison group [105]. Sustained response over 12-24 months may occur in $44-77 \%$ of patients $[106,107]$.

Vagus nerve stimulation surgery is relatively minor with few significant risks. Chronic stimulation also appears to be safe and well-tolerated. Potential stimulation-related side effects are only present during active stimulation and typically include mild voice changes, hoarseness, coughing and dysphagia. Chronic vagus nerve stimulation has generally not been associated with negative neuropsychological effects [108], though modest cognitive impairments may occur with higher stimulation parameters [109].

\section{Direct cortical stimulation}

With direct cortical stimulation, electrodes are surgically implanted directly onto the surface of the brain (usually epidurally) and stimulation is controlled through an implanted pulse generator. The rationale for direct cortical stimulation is similar to that for transcranial magnetic stimulation and transcranial direct current stimulation with the potentially added value that stimulation can potentially be given chronically, more focally and at higher intensities. Two small pilot studies have suggested potential benefit from direct cortical stimulation applied to the dorsolateral and/or medial prefrontal cortices in treatment-resistant depression patients, though relapse rates have not been reported $[110,111]$. Prefrontal direct cortical stimulation appears to be well-tolerated, though there are risks of bleeding and infection associated with surgery.

\section{Deep brain stimulation}

Deep brain stimulation involves implanting one or more electrodes into specific brain regions using stereotactic neurosurgical techniques; stimulation is controlled through an implantable pulse generator. Deep brain stimulation is an established treatment for many patients with medication-refractory movement disorders. Deep brain stimulation of the ventral anterior internal capsule and ventral striatum is FDA approved for patients with treatment-refractory obsessive-compulsive disorder under an FDA Humanitarian Device Exception (HDE); this was based on available open-label data since a definitive shamcontrolled trial was not performed [112]. The main risks of deep brain stimulation are associated with the implantation surgery (bleeding, infection, complications from anesthesia). Effects of acute and chronic stimulation largely depend on the brain site of stimulation.

A number of small, mostly open-label studies have examined the safety and efficacy of deep brain stimulation of various brain regions for treatment-resistant depression. The largest dataset exists for subcallosal cingulate white matter deep brain stimulation with targeting based on a converging database implicating this region and its connections in the neurobiology of the antidepressant response [113]. Remission rates with six months to several years of subcallosal cingulate stimulation are approximately 40-60\% [114-120]. For patients who remit, relapse has been uncommon. To date, there appear to be no adverse effects of acute or chronic subcallosal cingulate deep brain stimulation, including no neurocognitive impairments $[118,121]$, and an industry-sponsored pivotal trial of subcallosal cingulate deep brain stimulation for depression is currently underway. Subcallosal cingulate deep brain stimulation may operate through modulation of a mood regulation network such that patients are able to regulate mood appropriately and not remain "stuck" in the depressed state [4].

Small trials have shown similar efficacy for deep brain stimulation of the ventral anterior internal capsule and ventral striatum and nucleus accumbens for treatmentresistant depression [122-124]. The rationale for the first target came primarily from observations of antidepressant effects of ventral anterior internal capsule and ventral striatum deep brain stimulation in patients with obsessive compulsive disorder and comorbid depression [122]. The latter target was similarly justified with additional rationale provided by the prominence of anhedonia 
(the inability to feel pleasure) as a symptom of depression and the role of the nucleus accumbens in reward processing [125]. With both of these targets, acute stimulation was associated with a number of side effects including hypomania (a mild degree of mania), anxiety, perseverative speech (the persistent repetition of a word or phrase), autonomic symptoms and involuntary facial movements. These effects were reversible with changes in stimulation parameters, and there were no adverse effects of chronic deep brain stimulation, including no neuropsychological impairments. An industry-sponsored pivotal trial of ventral anterior internal capsule and ventral striatum deep brain stimulation for depression is currently underway.

Case reports have described potential antidepressant efficacy for deep brain stimulation of the inferior thalamic peduncle [126] and the habenula [127]. The inferior thalamic peduncle target was chosen based on its role in conveying thalamo-cortical information (an early rationale for ablative neurosurgical procedures). The habenula target was chosen based on its role in monoaminergic neurotransmission.

\section{Summary}

Electroconvulsive therapy and ablative neurosurgery are among the oldest neuromodulation techniques and are still the considered reasonable treatments for severe and treatment-resistant depression. Over the past two decades, neuromodulation, primarily in the form of focal brain stimulation, has re-emerged as a potential treatment option for depression. Transcranial magnetic stimulation, transcranial direct current stimulation, transcranial low voltage pulsed electromagnetic fields and magnetic seizure therapy are non-invasive and well-tolerated and may have a role in treating patients with a limited degree of treatment resistance (and perhaps as an alternative to medications or psychotherapy in certain patient populations). Vagus nerve stimulation, direct cortical stimulation and deep brain stimulation are more invasive with greater associated risks and will therefore likely play a role in treating more severely ill and treatment-resistant patients, presuming safety and efficacy are established in larger trials.

As the neurobiology of depression is still largely unknown, it is difficult to presume how various treatments for depression might work. The general rationale for neuromodulation in depression is that focal intervention in the neural network involved in mood regulation may have therapeutic effects by regulating the function of this network. With all of the above treatments, it is presumed that, if effective, modulation of network function occurs in a beneficial way. It remains an open question which nodes or pathways in the network must be affected for beneficial effect or whether different depressed patients may need different types of neuromodulation.

Going forward, it will be critically important to evaluate the acute versus long-term efficacy of these various treatments. As with electroconvulsive therapy, several of the above therapies (transcranial magnetic stimulation, transcranial direct current stimulation, transcranial low voltage pulsed electromagnetic fields, magnetic seizure therapy) are designed to provide acute treatment of the depressive episode. It is not yet clear how long the beneficial effects of these treatments last and whether they can successfully be used as "maintenance" treatments over time. Of the newer "acute" neuromodulation therapies, only transcranial magnetic stimulation has been subjected to a large number of sham-controlled studies, including two, large pivotal trials, with these trials demonstrating statistically significant acute efficacy. However, the longterm efficacy of transcranial magnetic stimulation and other "acute" neuromodulation therapies is not yet clear. Vagus nerve stimulation has not demonstrated acute antidepressant efficacy, but may have benefits over months to years; still, this has not been adequately established in the literature. For the other invasive treatments (direct current stimulation, deep brain stimulation), long-term effectiveness should be clearly demonstrated before these treatments are made available in standard clinical practice; in many ways, long-term efficacy of these treatments may be more important than acute efficacy.

Finally, it will be critically important to clarify which patients are appropriate for which treatments (e.g. based on level of treatment resistance or co-morbidities). This may be achieved through head-to-head trials comparing different neuromodulation approaches and through the use of well-constructed registries (for FDA-approved treatments). By investigating specific and shared mechanisms of action for these diverse treatments, biological factors predicting differential treatment response may be identified. These data may also identify new targets for treatment. Neuromodulation for depression is at an exciting and promising stage of development, and continued well-conducted research will help clarify and realize its potential.

\section{Abbreviation}

FDA, US Food and Drug Administration.

\section{Competing interests}

Dr. Holtzheimer receives consulting fees from St. Jude Medical Neuromodulation, a company engaged in a largescale, multi-center trial of a deep brain stimulation system for treatment-resistant depression. He also receives 
consulting fees from Cervel Neurotech, a company that is testing a transcranial magnetic stimulation system that may be able to stimulate deeper cortical structures.

\section{References}

I. WHO: The global burden of disease: 2004 update. In. Geneva; 2008.

2. Kessler RC, Chiu WT, Demler O, Merikangas KR, Walters EE: Prevalence, severity, and comorbidity of I 2-month DSM-IV disorders in the National Comorbidity Survey Replication. Arch Gen Psychiatry 2005, 62:617-27.

3. Rush AJ, Trivedi MH, Wisniewski SR, Nierenberg AA, Stewart JW, Warden D, Niederehe G, Thase ME, Lavori PW, Lebowitz BD, McGrath PJ, Rosenbaum JF, Sackeim HA, Kupfer DJ, Luther J, Fava M: Acute and longer-term outcomes in depressed outpatients requiring one or several treatment steps: a STAR*D report. Am J Psychiatry 2006, 163:1905-17.

4. Holtzheimer PE, Mayberg HS: Stuck in a rut: rethinking depression and its treatment. Trends Neurosci 20I I, 34:I-9.

5. Jasper $\mathrm{HH}$ : A historical perspective. The rise and fall of prefrontal lobotomy. Adv Neurol 1995, 66:97-II4.

6. Hariz Ml, Blomstedt P, Zrinzo L: Deep brain stimulation between 1947 and 1987: the untold story. Neurosurg Focus 2010, 29:EI.

7. Sachdev P, Sachdev J: Sixty years of psychosurgery: its present status and its future. Aust N Z J Psychiatry 1997, 3 I:457-64.

\section{FlOOOPrime \\ RECOMMENDED}

8. Marino Júnior R, Cosgrove GR: Neurosurgical treatment of neuropsychiatric illness. Psychiatr Clin North Am 1997, 20:933-43.

9. Bini L: Experimental researches on epileptic attacks induced by the electric current. Am J Psychiatry 1938, 94:172-4.

10. Sackeim HA, Haskett RF, Mulsant BH, Thase ME, Mann JJ, Pettinati HM, Greenberg RM, Crowe RR, Cooper TB, Prudic J: Continuation pharmacotherapy in the prevention of relapse following electroconvulsive therapy: a randomized controlled trial. JAMA 200I, 285: 1299-307.

II. Kellner $\mathrm{CH}$, Knapp RG, Petrides G, Rummans TA, Husain MM, Rasmussen K, Mueller M, Bernstein HJ, O'Connor K, Smith G, Biggs M, Bailine SH, Malur C, Yim E, McClintock S, Sampson S, Fink M: Continuation electroconvulsive therapy vs pharmacotherapy for relapse prevention in major depression: a multisite study from the Consortium for Research in Electroconvulsive Therapy (CORE). Arch Gen Psychiatry 2006, 63:1337-44.

\section{FlOOOPrime \\ RECOMMENDED}

12. Spellman T, Peterchev AV, Lisanby SH: Focal electrically administered seizure therapy: a novel form of ECT illustrates the roles of current directionality, polarity, and electrode configuration in seizure induction. Neuropsychopharmacology 2009, 34:2002-10.

13. Mayberg HS: Modulating dysfunctional limbic-cortical circuits in depression: towards development of brain-based algorithms for diagnosis and optimised treatment. Br Med Bull 2003, 65:193-207.

14. Drevets WC, Raichle ME: Neuroanatomical circuits in depression: implications for treatment mechanisms. Psychopharmacol Bull 1992, 28:26I-74.

\section{FlOOOPrime}

15. George MS, Lisanby SH, Sackeim HA: Transcranial magnetic stimulation: applications in neuropsychiatry. Arch Gen Psychiatry 1999, 56:300-II.

16. O'Reardon JP, Solvason HB, Janicak PG, Sampson S, Isenberg KE, Nahas Z, McDonald WM, Avery D, Fitzgerald PB, Loo C, Demitrack MA, George MS, Sackeim HA: Efficacy and safety of transcranial magnetic stimulation in the acute treatment of major depression: a multisite randomized controlled trial. Biol Psychiatry 2007, 62:1208-16.

\section{FIOOOPrime}

17. George MS, Lisanby SH, Avery D, McDonald WM, Durkalski V, Pavlicova M, Anderson B, Nahas Z, Bulow P, Zarkowski P, Holtzheimer PE, Schwartz T, Sackeim HA: Daily left prefrontal transcranial magnetic stimulation therapy for major depressive disorder: a sham-controlled randomized trial. Arch Gen Psychiatry 2010, 67:507-16.

\section{FlOOOPrime \\ RECOMMENDED}

18. Wassermann EM: Risk and safety of repetitive transcranial magnetic stimulation: report and suggested guidelines from the International Workshop on the Safety of Repetitive Transcranial Magnetic Stimulation, June 5-7, 1996. Electroencephalogr Clin Neurophysiol 1998, 108: I-16.

19. Burt T, Lisanby SH, Sackeim HA: Neuropsychiatric applications of transcranial magnetic stimulation: a meta analysis. Int J Neuropsychopharmacol 2002, 5:73-103.

20. Holtzheimer PE, Russo J, Avery DH: A meta-analysis of repetitive transcranial magnetic stimulation in the treatment of depression. Psychopharmacol Bull 200I, 35:149-69.

2I. Martin JLR, Barbanoj MJ, Schlaepfer TE, Thompson E, Pérez V, Kulisevsky J: Repetitive transcranial magnetic stimulation for the treatment of depression. Systematic review and metaanalysis. Br J Psychiatry 2003, I82:480-91.

22. Kozel FA, George MS: Meta-analysis of left prefrontal repetitive transcranial magnetic stimulation (rTMS) to treat depression. J Psychiatr Pract 2002, 8:270-5.

23. Schutter DJLG: Antidepressant efficacy of high-frequency transcranial magnetic stimulation over the left dorsolateral prefrontal cortex in double-blind sham-controlled designs: a meta-analysis. Psychol Med 2009, 39:65-75.

\section{FlOOOPrime} RECOMMENDED

24. Slotema CW, Blom JD, Hoek HW, Sommer IEC: Should we expand the toolbox of psychiatric treatment methods to include Repetitive Transcranial Magnetic Stimulation (rTMS)? A meta-analysis of the efficacy of rTMS in psychiatric disorders. J Clin Psychiatry 2010, 71:873-84.

\section{FlOOOPrime}

\section{RECOMMENDED}

25. Schutter DJLG: Quantitative review of the efficacy of slowfrequency magnetic brain stimulation in major depressive disorder. Psychol Med 2010, 40:1789-95.

26. George MS, Wassermann EM, Williams WA, Callahan A, Ketter TA, Basser $P$, Hallett $M$, Post RM: Daily repetitive transcranial magnetic stimulation (rTMS) improves mood in depression. Neuroreport 1995, 6: 1853-6.

\section{FlOOOPrime \\ RECOMMENDED}

27. Klein E, Kreinin I, Chistyakov A, Koren D, Mecz L, Marmur S, BenShachar D, Feinsod M: Therapeutic efficacy of right prefrontal slow repetitive transcranial magnetic stimulation in major depression: a double-blind controlled study. Arch Gen Psychiatry 1999, 56:315-20.

28. Pascual-Leone A, Rubio B, Pallardó F, Catalá MD: Rapid-rate transcranial magnetic stimulation of left dorsolateral prefrontal cortex in drug-resistant depression. Lancet 1996, 348:233-7.

29. Cho SS, Strafella AP: rTMS of the left dorsolateral prefrontal cortex modulates dopamine release in the ipsilateral anterior cingulate cortex and orbitofrontal cortex. PLOS ONE 2009, 4:e6725. 
30. Speer AM, Kimbrell TA, Wassermann EM, D Repella J, Willis MW, Herscovitch P, Post RM: Opposite effects of high and low frequency $\mathrm{rTMS}$ on regional brain activity in depressed patients. Biol Psychiatry 2000, 48: I I33-4I.

31. Grunhaus L, Dannon PN, Schreiber S, Dolberg OH, Amiaz R, Ziv R, Lefkifker E: Repetitive transcranial magnetic stimulation is as effective as electroconvulsive therapy in the treatment of nondelusional major depressive disorder: an open study. Biol Psychiatry 2000, 47:3।4-24.

32. Grunhaus L, Schreiber S, Dolberg OT, Polak D, Dannon PN: A randomized controlled comparison of electroconvulsive therapy and repetitive transcranial magnetic stimulation in severe and resistant nonpsychotic major depression. Biol Psychiatry 2003, 53:324-31.

33. Janicak PG, Dowd S, Rado J, Welch MJ, Fogg L, O'Reardon J, Avery D, Coffey CE, Sampson S, Boutros N: Repetitive transcranial magnetic stimulation versus electroconvulsive therapy: efficacy of treatment in nonpsychotic patients with depression. Am J Psychiatry 2007, 164: I I 8; author reply III8-9.

34. Pridmore S, Bruno R, Turnier-Shea Y, Reid P, Rybak M: Comparison of unlimited numbers of rapid transcranial magnetic stimulation (rTMS) and ECT treatment sessions in major depressive episode. Int J Neuropsychopharmacol 2000, 3:129-34.

35. Eranti S, Mogg A, Pluck G, Landau S, Purvis R, Brown RG, Howard R, Knapp M, Philpot M, Rabe-Hesketh S, Romeo R, Rothwell J, Edwards D, McLoughlin DM: A randomized, controlled trial with 6-month follow-up of repetitive transcranial magnetic stimulation and electroconvulsive therapy for severe depression. Am J Psychiatry 2007, 164:73-81.

36. Knapp M, Romeo R, Mogg A, Eranti S, Pluck G, Purvis R, Brown RG, Howard R, Philpot M, Rothwell J, Edwards D, McLoughlin DM: Costeffectiveness of transcranial magnetic stimulation vs. electroconvulsive therapy for severe depression: a multi-centre randomised controlled trial. J Affect Disord 2008, 109:273-85.

37. Rosa MA, Gattaz WF, Pascual-Leone A, Fregni F, Rosa MO, Rumi DO, Myczkowski M, Silva MF, Mansur C, Rigonatti SP, Jacobsen Teixeira M, Marcolin MA: Comparison of repetitive transcranial magnetic stimulation and electroconvulsive therapy in unipolar nonpsychotic refractory depression: a randomized, single-blind study. Int J Neuropsychopharmacol 2006, 9:667-76.

\section{FlOOOPrime}

38. Hansen PEB, Ravnkilde B, Videbech P, Clemmensen K, Sturlason R, Reiner M, Parner E, Rosenberg R, Vestergaard P: Low-frequency repetitive transcranial magnetic stimulation inferior to electroconvulsive therapy in treating depression. J ECT 20I I, 27:26-32.

39. Fitzgerald PB: Repetitive transcranial magnetic stimulation is not as effective as electroconvulsive therapy for major depression. Evid Based Ment Health 2007, 10:78.

40. Keshtkar M, Ghanizadeh A, Firoozabadi A: Repetitive transcranial magnetic stimulation versus electroconvulsive therapy for the treatment of major depressive disorder, a randomized controlled clinical trial. J ECT 20II, 27:310-4.

\section{FlOOOPrime}

41. Kim DR, Epperson N, Paré E, Gonzalez JM, Parry S, Thase ME, Cristancho P, Sammel MD, O'Reardon JP: An open label pilot study of transcranial magnetic stimulation for pregnant women with major depressive disorder. J Womens Health (Larchmt) 20II, 20:255-6I.

\section{FlOOOPrime}

42. Garcia KS, Flynn P, Pierce KJ, Caudle M: Repetitive transcranial magnetic stimulation treats postpartum depression. Brain Stimul 20I0, 3:36-4I.

FlOOOPrime RECOMMENDED
43. Nahas Z, Molloy MA, Hughes PL, Oliver NC, Arana GW, Risch SC, George MS: Repetitive transcranial magnetic stimulation: perspectives for application in the treatment of bipolar and unipolar disorders. Bipolar Disord 1999, I:73-80.

44. Zhang X, Liu K, Sun J, Zheng Z: Safety and feasibility of repetitive transcranial magnetic stimulation (rTMS) as a treatment for major depression during pregnancy. Arch Womens Ment Health 2010, 13:369-70

\section{FlOOOPrime}

\section{RECOMMENDED}

45. Klirova M, Novak T, Kopecek M, Mohr P, Strunzova V: Repetitive transcranial magnetic stimulation (rTMS) in major depressive episode during pregnancy. Neuro Endocrinol Lett 2008, 29:69-70.

46. Croarkin PE, Wall CA, McClintock SM, Kozel FA, Husain MM, Sampson SM: The emerging role for repetitive transcranial magnetic stimulation in optimizing the treatment of adolescent depression. J ECT 2010, 26:323-9.

\section{FlOOOPrime}

\section{RECOMMENDED}

47. D'Agati $D$, Bloch $Y$, Levkovitz $Y$, Reti I: rTMS for adolescents: Safety and efficacy considerations. Psychiatry Res 2010, 177:280-5.

48. Bloch Y, Grisaru N, Harel EV, Beitler G, Faivel N, Ratzoni G, Stein D, Levkovitz $Y$ : Repetitive transcranial magnetic stimulation in the treatment of depression in adolescents: an open-label study. J ECT 2008, 24: I56-9.

49. Quintana $\mathrm{H}$ : Transcranial magnetic stimulation in persons younger than the age of 18. J ECT 2005, 21:88-95.

50. Loo C, McFarquhar T, Walter G: Transcranial magnetic stimulation in adolescent depression. Australas Psychiatry 2006, I4:8I-5.

5I. Walter G, Tormos JM, Israel JA, Pascual-Leone A: Transcranial magnetic stimulation in young persons: a review of known cases. J Child Adolesc Psychopharmacol 200 I, I I:69-75.

52. Figiel GS, Epstein C, McDonald WM, Amazon-Leece J, Figiel L, Saldivia A, Glover $S$ : The use of rapid-rate transcranial magnetic stimulation (rTMS) in refractory depressed patients. J Neuropsychiatry Clin Neurosci 1998, 10:20-5.

53. Milev R, Abraham G, Hasey G, Cabaj JL: Repetitive transcranial magnetic stimulation for treatment of medication-resistant depression in older adults: a case series. J ECT 2009, 25:44-9.

54. Abraham G, Milev R, Lazowski L, Jokic R, Du Toit R, Lowe A: Repetitive transcranial magnetic stimulation for treatment of elderly patients with depression - an open label trial. Neuropsychiatr Dis Treat 2007, 3:919-24.

\section{FlOOOPrime
RECOMMENDED}

55. Jorge RE, Robinson RG, Tateno A, Narushima K, Acion L, Moser D, Arndt S, Chemerinski E: Repetitive transcranial magnetic stimulation as treatment of poststroke depression: a preliminary study. Biol Psychiatry 2004, 55:398-405.

56. Jorge RE, Moser DJ, Acion L, Robinson RG: Treatment of vascular depression using repetitive transcranial magnetic stimulation. Arch Gen Psychiatry 2008, 65:268-76.

57. Fabre I, Galinowski A, Oppenheim C, Gallarda T, Meder JF, Montigny $C$ de, Olié JP, Poirier MF: Antidepressant efficacy and cognitive effects of repetitive transcranial magnetic stimulation in vascular depression: an open trial. Int J Geriatr Psychiatry 2004, 19:833-42.

\section{FlOOOPrime
RECOMMENDED}

58. Dannon PN, Dolberg OT, Schreiber S, Grunhaus L: Three and sixmonth outcome following courses of either ECT or rTMS in a population of severely depressed individuals-preliminary report. Biol Psychiatry 2002, 5 I:687-90.

59. Avery DH, Holtzheimer PE, Fawaz W, Russo J, Neumaier J, Dunner DL, Haynor DR, Claypoole KH, Wajdik C, Roy-Byrne P: A controlled study of repetitive transcranial magnetic 
stimulation in medication-resistant major depression. Biol Psychiatry 2006, 59:187-94.

60. Mantovani A, Pavlicova M, Avery D, Nahas Z, McDonald WM, Wajdik CD, Holtzheimer PE, George MS, Sackeim HA, Lisanby SH: Long-term efficacy of repeated daily prefrontal transcranial magnetic stimulation (TMS) in treatment-resistant depression. Depress Anxiety 2012, 29:883-90.

61. Janicak PG, Nahas Z, Lisanby SH, Solvason HB, Sampson SM, McDonald WM, Marangell LB, Rosenquist P, McCall WV, Kimball J, O'Reardon JP, Loo C, Husain MH, Krystal A, Gilmer W, Dowd SM, Demitrack MA, Schatzberg AF: Durability of clinical benefit with transcranial magnetic stimulation (TMS) in the treatment of pharmacoresistant major depression: assessment of relapse during a 6-month, multisite, open-label study. Brain Stimul 2010 , 3:187-99.

62. Demirtas-Tatlidede A, Mechanic-Hamilton D, Press DZ, Pearlman C, Stern WM, Thall M, Pascual-Leone A: An open-label, prospective study of repetitive transcranial magnetic stimulation (rTMS) in the long-term treatment of refractory depression: reproducibility and duration of the antidepressant effect in medication-free patients. J Clin Psychiatry 2008, 69:930-4.

\section{FlOOPrime} RECOMMENDED

63. Dragasevic N, Potrebić A, Damjanović A, Stefanova E, Kostić VS: Therapeutic efficacy of bilateral prefrontal slow repetitive transcranial magnetic stimulation in depressed patients with Parkinson's disease: an open study. Mov Disord 2002, 17:528-32.

64. Loo CK, Mitchell PB, Croker VM, Malhi GS, Wen W, Gandevia SC, Sachdev PS: Double-blind controlled investigation of bilateral prefrontal transcranial magnetic stimulation for the treatment of resistant major depression. Psychol Med 2003, 33:33-40.

65. Conca A, Di Pauli J, Beraus W, Hausmann A, Peschina W, Schneider $\mathrm{H}$, König $\mathrm{P}$, Hinterhuber $\mathrm{H}$ : Combining high and low frequencies in rTMS antidepressive treatment: preliminary results. Hum Psychopharmacol 2002, 17:353-6.

66. Fitzgerald PB, Benitez J, Castella A de, Daskalakis ZJ, Brown TL, Kulkarni J: A randomized, controlled trial of sequential bilateral repetitive transcranial magnetic stimulation for treatment-resistant depression. Am J Psychiatry 2006, 163:88-94.

\section{FlOOOPrime}

\section{RECOMMENDED}

67. Hausmann A, Kemmler G, Walpoth M, Mechtcheriakov S, KramerReinstadler K, Lechner T, Walch T, Deisenhammer EA, Kofler M, Rupp $\mathrm{Cl}$, Hinterhuber $\mathrm{H}$, Conca $\mathrm{A}$ : No benefit derived from repetitive transcranial magnetic stimulation in depression: a prospective, single centre, randomised, double blind, sham controlled “add on” trial. J Neurol Neurosurg Psychiatr 2004, 75:320-2.

68. McDonald WM, Easley K, Byrd EH, Holtzheimer P, Tuohy S, Woodard JL, Beyer K, Epstein CM: Combination rapid transcranial magnetic stimulation in treatment refractory depression. Neuropsychiatr Dis Treat 2006, 2:85-94.

69. Fadini T, Matthäus L, Rothkegel H, Sommer M, Tergau F, Schweikard A, Paulus W, Nitsche MA: H-coil: Induced electric field properties and input/output curves on healthy volunteers, comparison with a standard figure-of-eight coil. Clin Neurophysiol 2009, I 20: I 174-82.

70. Harel EV, Zangen A, Roth Y, Reti I, Braw Y, Levkovitz Y: H-coil repetitive transcranial magnetic stimulation for the treatment of bipolar depression: an add-on, safety and feasibility study. World J Biol Psychiatry 201 I, I2:1 19-26.

7I. Levkovitz Y, Roth Y, Harel EV, Braw Y, Sheer A, Zangen A: $A$ randomized controlled feasibility and safety study of deep transcranial magnetic stimulation. Clin Neurophysiol 2007, I | 8:2730-44

72. Zangen $A$, Roth $Y$, Voller B, Hallett $M$ : Transcranial magnetic stimulation of deep brain regions: evidence for efficacy of the H-coil. Clin Neurophysiol 2005, I I 6:775-9.

73. Levkovitz $Y$, Harel EV, Roth $Y$, Braw $Y$, Most D, Katz LN, Sheer A, Gersner R, Zangen A: Deep transcranial magnetic stimulation over the prefrontal cortex: evaluation of antidepressant and cognitive effects in depressive patients. Brain Stimul 2009, 2:188-200

74. Holzer M, Padberg F: Intermittent theta burst stimulation (iTBS) ameliorates therapy-resistant depression: a case series. Brain Stimul 2010, 3:181-3.

75. Wu C, Tsai C, Lu M, Chen C, Shen W, Su K: Theta-burst repetitive transcranial magnetic stimulation for treatmentresistant obsessive-compulsive disorder with concomitant depression. J Clin Psychiatry 2010, 7I:504-6.

76. Chistyakov AV, Rubicsek O, Kaplan B, Zaaroor M, Klein E: Safety, tolerability and preliminary evidence for antidepressant efficacy of theta-burst transcranial magnetic stimulation in patients with major depression. Int ] Neuropsychopharmacol 2010, 13:387-93.

77. Hadley D, Anderson BS, Borckardt JJ, Arana A, Li X, Nahas Z, George MS: Safety, tolerability, and effectiveness of high doses of adjunctive daily left prefrontal repetitive transcranial magnetic stimulation for treatment-resistant depression in a clinical setting. J ECT 201।, 27:18-25.

78. Holtzheimer PE, McDonald WM, Mufti M, Kelley ME, Quinn S, Corso G, Epstein CM: Accelerated repetitive transcranial magnetic stimulation for treatment-resistant depression. Depress Anxiety 2010, 27:960-3.

\section{FlOOOPrime
RECOMMENDED}

79. Nitsche MA, Boggio PS, Fregni F, Pascual-Leone A: Treatment of depression with transcranial direct current stimulation (tDCS): a review. Exp Neurol 2009, 2 I9:14-9.

80. Poreisz C, Boros K, Antal A, Paulus W: Safety aspects of transcranial direct current stimulation concerning healthy subjects and patients. Brain Res Bull 2007, 72:208-I4.

8I. Arul-Anandam AP, Loo C, Mitchell P: Induction of hypomanic episode with transcranial direct current stimulation. J ECT 2010, 26:68-9

82. Fregni F, Boggio PS, Nitsche MA, Marcolin MA, Rigonatti SP, PascualLeone A: Treatment of major depression with transcranial direct current stimulation. Bipolar Disord 2006, 8:203-4.

83. Loo CK, Sachdev P, Martin D, Pigot M, Alonzo A, Malhi GS, Lagopoulos J, Mitchell P: A double-blind, sham-controlled trial of transcranial direct current stimulation for the treatment of depression. Int J Neuropsychopharmacol 2010, 13:6I-9.

\section{FlOOOPrime \\ RECOMMENDED}

84. Requena Caballero L, Vázquez López F, Requena Caballero C, Urrutia Hernando S, Sánchez López M, Sánchez Yus E, Hernández Moro B: Metastatic umbilical cancer-Sister Mary Joseph's nodule: report of two cases. J Dermatol Surg Oncol 1988, I4:664-7.

85. Loo CK, Alonzo A, Martin D, Mitchell PB, Galvez V, Sachdev P. Transcranial direct current stimulation for depression: 3-week, randomised, sham-controlled trial. Br J Psychiatry 2012, 200:52-9.

86. Dell'Osso B, Priori A, Altamura AC: Efficacy and safety of transcranial direct current stimulation in major depression. Biol Psychiatry 2011, 69:e23-4.

87. Palm U, Schiller C, Fintescu Z, Obermeier M, Keeser D, Reisinger E, Pogarell O, Nitsche MA, Möller H, Padberg F: Transcranial direct current stimulation in treatment resistant depression: A randomized double-blind, placebo-controlled study. Brain Stimul 2012, 5:242-5I.

\section{FlOOOPrime \\ RECOMMENDED}

88. Brunoni AR, Valiengo L, Baccaro A, Zanao TA, Oliveira JF de, Vieira GP, Bueno VF, Goulart AC, Boggio PS, Lotufo PA, Bensenor IM, Fregni F: Sertraline vs. ELectrical Current Therapy for Treating Depression Clinical Trial-SELECT TDCS: design, rationale and objectives. Contemp Clin Trials 20I I, 32:90-8. 
89. Martiny K, Lunde M, Bech P: Transcranial low voltage pulsed electromagnetic fields in patients with treatment-resistant depression. Biol Psychiatry 2010, 68:163-9.

\section{FlOOOPrime}

\section{RECOMMENDED}

90. Lisanby SH, Luber B, Schlaepfer TE, Sackeim HA: Safety and feasibility of magnetic seizure therapy (MST) in major depression: randomized within-subject comparison with electroconvulsive therapy. Neuropsychopharmacology 2003, 28:1852-65.

91. Kosel M, Frick C, Lisanby SH, Fisch H, Schlaepfer TE: Magnetic seizure therapy improves mood in refractory major depression. Neuropsychopharmacology 2003, 28:2045-8.

92. Baines CJ, Christen A, Simard A, Wall C, Dean D, Duncan L, Edward P, Fryer ML, Grégoire LB, May C: The National Breast Screening Study: pre-recruitment sources of awareness in participants. Can J Public Health 1989, 80:221-5.

93. White PF, Amos Q, Zhang Y, Stool L, Husain MM, Thornton L, Downing M, McClintock S, Lisanby SH: Anesthetic considerations for magnetic seizure therapy: a novel therapy for severe depression. Anesth Analg 2006, 103:76-80, table of contents.

94. Kayser S, Bewernick BH, Grubert C, Hadrysiewicz BL, Axmacher N, Schlaepfer TE: Antidepressant effects, of magnetic seizure therapy and electroconvulsive therapy, in treatment-resistant depression. J Psychiatr Res 20II, 45:569-76.

\section{FlOOOPrime}

\section{RECOMMENDED}

95. Elger G, Hoppe C, Falkai P, Rush AJ, Elger CE: Vagus nerve stimulation is associated with mood improvements in epilepsy patients. Epilepsy Res 2000, 42:203-10.

96. Harden CL, Pulver MC, Ravdin LD, Nikolov B, Halper JP, Labar DR: A Pilot Study of Mood in Epilepsy Patients Treated with Vagus Nerve Stimulation. Epilepsy Behav 2000, I:93-9.

97. Nemeroff CB, Mayberg HS, Krahl SE, McNamara J, Frazer A, Henry TR, George MS, Charney DS, Brannan SK: VNS therapy in treatment-resistant depression: clinical evidence and putative neurobiological mechanisms. Neuropsychopharmacology 2006, 31: I345-55.

98. Sackeim HA, Rush AJ, George MS, Marangell LB, Husain MM, Nahas Z, Johnson CR, Seidman S, Giller C, Haines S, Simpson RK, Goodman RR: Vagus nerve stimulation (VNS) for treatmentresistant depression: efficacy, side effects, and predictors of outcome. Neuropsychopharmacology 200I, 25:713-28.

99. Schlaepfer TE, Frick C, Zobel A, Maier W, Heuser I, Bajbouj M, O'Keane V, Corcoran C, Adolfsson R, Trimble M, Rau H, Hoff H, Padberg F, Müller-Siecheneder F, Audenaert K, van den Abbeele D, Matthews K, Christmas D, Stanga Z, Hasdemir M: Vagus nerve stimulation for depression: efficacy and safety in a European study. Psychol Med 2008, 38:65I-6I.

100. Rush AJ, Sackeim HA, Marangell LB, George MS, Brannan SK, Davis SM, Lavori P, Howland R, Kling MA, Rittberg B, Carpenter L, Ninan P, Moreno F, Schwartz T, Conway C, Burke M, Barry J]: Effects of 12 months of vagus nerve stimulation in treatmentresistant depression: a naturalistic study. Biol Psychiatry 2005, 58:355-63.

101. Marangell LB, Rush AJ, George MS, Sackeim HA, Johnson CR, Husain MM, Nahas Z, Lisanby SH: Vagus nerve stimulation (VNS) for major depressive episodes: one year outcomes. Biol Psychiatry 2002, 5 I:280-7.

102. Nahas Z, Marangell LB, Husain MM, Rush AJ, Sackeim HA, Lisanby SH, Martinez JM, George MS: Two-year outcome of vagus nerve stimulation (VNS) for treatment of major depressive episodes. J Clin Psychiatry 2005, 66:1097-104.

103. Cristancho P, Cristancho MA, Baltuch GH, Thase ME, O'Reardon JP: Effectiveness and safety of vagus nerve stimulation for severe treatment-resistant major depression in clinical practice after FDA approval: outcomes at I year. J Clin Psychiatry 201 I, 72:1376-82

104. Rush AJ, Marangell LB, Sackeim HA, George MS, Brannan SK, Davis SM, Howland R, Kling MA, Rittberg BR, Burke WJ,
Rapaport MH, Zajecka J, Nierenberg AA, Husain MM, Ginsberg D, Cooke RG: Vagus nerve stimulation for treatment-resistant depression: a randomized, controlled acute phase trial. Biol Psychiatry 2005, 58:347-54

\section{FlOOOPrime
RECOMMENDED}

105. George MS, Rush AJ, Marangell LB, Sackeim HA, Brannan SK, Davis SM, Howland R, Kling MA, Moreno F, Rittberg B, Dunner D, Schwartz T, Carpenter L, Burke M, Ninan P, Goodnick P: A one-year comparison of vagus nerve stimulation with treatment as usual for treatment-resistant depression. Biol Psychiatry 2005, 58:364-73.

106. Sackeim HA, Brannan SK, Rush AJ, George MS, Marangell LB, Allen J: Durability of antidepressant response to vagus nerve stimulation (VNS). Int J Neuropsychopharmacol 2007, 10:817-26.

107. Bajbouj M, Merkl A, Schlaepfer TE, Frick C, Zobel A, Maier W, O'Keane V, Corcoran C, Adolfsson R, Trimble M, Rau H, Hoff $\mathrm{H}$, Padberg F, Müller-Siecheneder F, Audenaert K, van den Abbeele D, Matthews K, Christmas D, Eljamel S, Heuser I: Two-year outcome of vagus nerve stimulation in treatment-resistant depression. J Clin Psychopharmacol 2010, 30:273-8I.

108. Moreines JL, McClintock SM, Holtzheimer PE: Neuropsychologic effects of neuromodulation techniques for treatment-resistant depression: a review. Brain Stimul 201 I, 4:17-27.

109. Helmstaedter C, Hoppe C, Elger CE: Memory alterations during acute high-intensity vagus nerve stimulation. Epilepsy Res 200I, 47:37-42.

\section{FlOOOPrime} RECOMMENDED

1 10. Nahas Z, Anderson BS, Borckardt J, Arana AB, George MS, Reeves ST, Takacs I: Bilateral epidural prefrontal cortical stimulation for treatment-resistant depression. Biol Psychiatry 2010, 67:101-9.

III. Kopell BH, Halverson J, Butson CR, Dickinson M, Bobholz J, Harsch H, Rainey C, Kondziolka D, Howland R, Eskandar E, Evans KC, Dougherty DD: Epidural cortical stimulation of the left dorsolateral prefrontal cortex for refractory major depressive disorder. Neurosurgery 2011, 69:1015-29; discussion 1029.

112. Greenberg BD, Gabriels LA, Malone DA, Rezai AR, Friehs GM, Okun MS, Shapira NA, Foote KD, Cosyns PR, Kubu CS, Malloy PF, Salloway SP, Giftakis JE, Rise MT, Machado AG, Baker KB, Stypulkowski PH, Goodman WK, Rasmussen SA, Nuttin BJ: Deep brain stimulation of the ventral internal capsule/ventral striatum for obsessive-compulsive disorder: worldwide experience. Mol Psychiatry 2010, 15:64-79.

1 13. Mayberg HS: Targeted electrode-based modulation of neural circuits for depression. J Clin Invest 2009, I 19:7 I7-25.

114. Mayberg HS, Lozano AM, Voon V, McNeely HE, Seminowicz D, Hamani C, Schwalb JM, Kennedy SH: Deep brain stimulation for treatment-resistant depression. Neuron 2005, 45:65I-60.

\section{FlOOOPrime}

\section{RECOMMENDED}

115. Lozano AM, Mayberg HS, Giacobbe P, Hamani C, Craddock RC, Kennedy SH: Subcallosal cingulate gyrus deep brain stimulation for treatment-resistant depression. Biol Psychiatry 2008, 64:46I-7.

\section{FlOOOPrime
RECOMMENDED}

116. Lozano AM, Giacobbe P, Hamani C, Rizvi SJ, Kennedy SH, Kolivakis TT, Debonnel G, Sadikot AF, Lam RW, Howard AK, Ilcewicz-Klimek M, Honey CR, Mayberg HS: A multicenter pilot study of subcallosal cingulate area deep brain stimulation for treatment-resistant depression. J Neurosurg 20I2, I 16:3 I5-22.

117. Kennedy SH, Giacobbe P, Rizvi SJ, Placenza FM, Nishikawa Y, Mayberg HS, Lozano AM: Deep brain stimulation for treatmentresistant depression: follow-up after 3 to 6 years. Am J Psychiatry 201I, 168:502-10. 
I 18. Holtzheimer PE, Kelley ME, Gross RE, Filkowski MM, Garlow S], Barrocas A, Wint D, Craighead MC, Kozarsky J, Chismar R, Moreines JL, Mewes K, Posse PR, Gutman DA, Mayberg HS: Subcallosal cingulate deep brain stimulation for treatmentresistant unipolar and bipolar depression. Arch Gen Psychiatry 2012, 69:150-8.

\section{FlOOOPrime}

\section{RECOMMENDED}

119. Puigdemont D, Pérez-Egea R, Portella MJ, Molet J, Diego-Adeliño J de, Gironell A, Radua J, Gómez-Anson B, Rodríguez R, Serra M, Quintana $C$ de, Artigas F, Alvarez E, Pérez V: Deep brain stimulation of the subcallosal cingulate gyrus: further evidence in treatment-resistant major depression. Int J Neuropsychopharmacol 201 I:I-I3.

120. Guinjoan SM, Mayberg HS, Costanzo EY, Fahrer RD, Tenca E, Antico J, Cerquetti D, Smyth E, Leiguarda RC, Nemeroff CB: Asymmetrical contribution of brain structures to treatment-resistant depression as illustrated by effects of right subgenual cingulum stimulation. J Neuropsychiatry Clin Neurosci 2010, 22: 265-77.

12I. McNeely HE, Mayberg HS, Lozano AM, Kennedy SH: Neuropsychological impact of $\mathrm{Cg} 25$ deep brain stimulation for treatmentresistant depression: preliminary results over 12 months. J Nerv Ment Dis 2008, 196:405-10.

122. Malone DA, Dougherty DD, Rezai AR, Carpenter LL, Friehs GM, Eskandar EN, Rauch SL, Rasmussen SA, Machado AG, Kubu CS, Tyrka AR, Price LH, Stypulkowski PH, Giftakis JE, Rise MT, Malloy PF, Salloway SP, Greenberg BD: Deep brain stimulation of the ventral capsule/ventral striatum for treatment-resistant depression. Biol Psychiatry 2009, 65:267-75.

123. Bewernick BH, Hurlemann R, Matusch A, Kayser S, Grubert C, Hadrysiewicz B, Axmacher N, Lemke M, Cooper-Mahkorn D, Cohen MX, Brockmann H, Lenartz D, Sturm V, Schlaepfer TE: Nucleus accumbens deep brain stimulation decreases ratings of depression and anxiety in treatment-resistant depression. Biol Psychiatry 2010, 67:110-6.

124. Bewernick BH, Kayser S, Sturm V, Schlaepfer TE: Long-term effects of nucleus accumbens deep brain stimulation in treatmentresistant depression: evidence for sustained efficacy. Neuropsychopharmacology 2012, 37:1975-85.

125. Schlaepfer TE, Cohen MX, Frick C, Kosel M, Brodesser D, Axmacher N, Joe AY, Kreft M, Lenartz D, Sturm V: Deep brain stimulation to reward circuitry alleviates anhedonia in refractory major depression. Neuropsychopharmacology 2008, 33:368-77.

\section{FlOOOPrime}

\section{RECOMMENDED}

126. Jiménez $F$, Velasco $F$, Salin-Pascual $R$, Hernández JA, Velasco $M$, Criales JL, Nicolini H: A patient with a resistant major depression disorder treated with deep brain stimulation in the inferior thalamic peduncle. Neurosurgery 2005, 57:585-93; discussion 585-93.

127. Sartorius A, Kiening KL, Kirsch P, Gall CC von, Haberkorn U, Unterberg AW, Henn FA, Meyer-Lindenberg A: Remission of major depression under deep brain stimulation of the lateral habenula in a therapy-refractory patient. Biol Psychiatry 2010, 67:e9-ell. 